\title{
CARACTERIZAÇÃO DE CATALISADORES UTILIZADOS NA REAÇÃO SHIFT
}

\author{
T. C. FERRARI ${ }^{1}$, A. C. FORNARI ${ }^{1}$, M. O. CAMARGO ${ }^{1}$, R. MENECHINI NETO ${ }^{1}$, R. M. M. \\ JORGE $^{2}$, M. H. N. OLSEN ESCALIANTE ${ }^{1}$ e L. M. M. JORGE ${ }^{1}$ \\ ${ }^{1}$ Universidade Estadual de Maringá, Departamento de Engenharia Química \\ ${ }^{2}$ Universidade Federal do Paraná, Departamento de Engenharia Química \\ E-mail para contato: taticferrari@gmail.com
}

\begin{abstract}
RESUMO - O monóxido de carbono é um veneno para Células a Combustíveis tipo PEFC quando se apresenta com teor acima de $50 \mathrm{mg} \mathrm{L}^{-1}$ na corrente de alimentação, proveniente de um reator de reforma a vapor de metanol. Por sua vez, o $\mathrm{CO}$ pode ser removido promovendo-se a reação shift $\left(\mathrm{CO}+\mathrm{H}_{2} \mathrm{O} \leftrightarrow \mathrm{CO}_{2}+\mathrm{H}_{2}\right)$ num reator de leito fixo, recheado com catalisador a base de cobre e zinco suportados em alumina. A caracterização dos catalisadores empregados neste processo é de grande importância para explicar, prever e justificar algumas de suas principais propriedades, tais como atividade, seletividade e estabilidade. Neste contexto, foram caracterizados três catalisadores: dois comerciais (HiFUEL ${ }^{\mathrm{TM}}$ W220 e W230, Alfa Aesar) e um sintetizado em laboratório pelo método sol-gel com a mesma composição destes. As caracterizações realizadas foram: área BET, volume específico e diâmetro médio de poros; DRX; TPR; TGA e DSC. Os resultados revelam diferenças significativas entre os catalisadores comerciais e o sintetizado, mostrando que este último possui grande área superficial (embora menor se comparada com os catalisadores industriais) e uma maior cristabilidade e redução.
\end{abstract}

\section{INTRODUÇÃO}

Os combustíveis fósseis, como petróleo e carvão, além de submeterem os países à instabilidade de preços e gerarem resíduos que comprometem as condições ambientais, um dia estarão esgotados. Deste modo, torna-se atrativa a busca de rotas alternativas para geração de energia (Sun et al., 2004).

Um sistema de célula de combustível do tipo PEFC, por exemplo, foi considerada adequada para um gerador para veículos e aplicações portáteis. Em comparação com o hidrogênio gasoso, metanol pode ser facilmente manuseado e transportado como um combustível líquido sob condições ambiente. $\mathrm{O}$ hidrogênio é facilmente produzido a partir de metanol por reforma a vapor em baixas temperaturas (200$400^{\circ} \mathrm{C}$ ) (Tanaka et al., 2003). No entanto, no caso da aplicação de PEFC, uma pequena quantidade de CO no combustível reformado deteriora o eletrodo de Pt e o desempenho da célula. É, portanto, necessário remover traços de CO nos gases de reforma (Utaka et al., 2000).

Atualmente os catalisadores estudas para a reação shift são à base de $\mathrm{Cu}$ ou $\mathrm{Pt}$ (Koryabkina et al., 2003). No entanto, os catalisadores à base de $\mathrm{Cu}$ são mais viáveis economicamente, além de que, o 


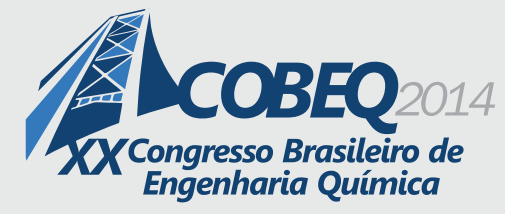

catalisador $\mathrm{Cu} / \mathrm{ZnO} / \mathrm{Al}_{2} \mathrm{O}_{3}$, por exemplo, exibe uma elevada atividade catalítica, mesmo em temperaturas entre 200 e $300^{\circ} \mathrm{C}$ (Tanaka et al., 2003). Óxido de cobre já é utilizado em catalisadores comerciais para WGSR, no entanto, a procura de melhoria das propriedades físico-químicas do sistema catalítico tem sido objeto de vários estudos (Maciel et al., 2013). Bunluesin et al. (1998) utilizaram cério como suporte de platina, paládio e ródio e Andreeva et al. (2002) utilizaram catalisadores a base de ouro. Uma possibilidade seria a sintetização de um catalisador pelo método sol-gel. O método sol-gel representa uma alternativa vantajosa para a síntese de catalisadores, pois conduz a materiais mais homogêneos, com alta porosidade e dispersão da fase ativa (Gonçalves et al., 2006; Colpini et al., 2013). Entretanto, não há referências sobre a utilização desta técnica para a síntese de catalisadores aplicados na reação de watergas shift.

A aplicação de diversas técnicas de caracterização é de grande importância para explicar, prever e justificar algumas das principais propriedades dos catalisadores, tais como atividade, seletividade e estabilidade. Neste contexto, foram caracterizados dois catalisadores empregados industrialmente na reação shift: o catalisador HiFUEL W220 (low temperature) e o HiFUEL W230 (medium temperature), ambos fabricados por Alfa Aesar/Johnson Matthey. Além disso, também foi sintetizado um catalisador pelo método sol-gel com a composição semelhante industrial e caracterizado igual aos demais.

\section{PROCEDIMENTO EXPERIMENTAL}

\subsection{Síntese do Catalisador Sol-Gel}

O catalisador sol-gel foi sintetizado seguindo-se a metodologia proposta por Pearson et al. (1983) e modificada por Santos (1999) e Lenzi et al. (2011) mantendo-se constante a proporção mássica cobre/zinco de 1,66 (proporção mássica $\mathrm{Cu} / \mathrm{Zn}$ do catalisador comercial utilizado para a reação shift HiFUEL W220 e HiFUEL W230, Alfa Aesar ${ }^{\circledR}$ ). As massas dos reagentes foram calculadas e aferidas de acordo com a concentração desejada dos metais no catalisador.

As composições dos metais no catalisador foram obtidas através de espectroscopia de absorção atômica (Varian, Atomic Absorption Spectrometer SpectrAA 50B) após a abertura (dissolução) das amostras. No caso do catalisador comercial, a composição esperada é a fornecida na ficha técnica do produto e a composição real é a que consta na ficha de análise do lote utilizado em particular. Na Tabela 1 as porcentagens e frações são expressas na forma mássica.

Tabela 1 - Composições dos catalisadores

\begin{tabular}{c|c|c|c|c|c|c}
\hline Catalisador & \% Cu & \% Zn & \%Al & Razão Cu/Zn & Razão Cu/Al & Razão Zn/Al \\
\hline Sol-gel & 40,6 & 23,1 & 9,0 & 1,76 & 4,52 & 2,57 \\
\hline W220 & 52,5 & 30,2 & 17,0 & 1,74 & 3,09 & 1,78 \\
\hline W230 & 50,2 & 30,8 & 18,7 & 1,63 & 2,68 & 1,65 \\
\hline
\end{tabular}

\subsection{Caracterizações dos Catalisadores}


As caracterizações foram feitas com partículas trituradas e peneiradas de diâmetro $0,6 \mathrm{~mm}<\mathrm{d}<$ $0,85 \mathrm{~mm}$, com exceção da difração de raios $\mathrm{X}$ (onde o diâmetro utilizado foi $<0,6 \mathrm{~mm}$ ).

TGA-DSC: A TGA se baseia na perda de massa da amostra quando submetida a um aumento gradual e constante de temperatura. A DSC é uma medida de fluxo de calor, que permite identificar mudanças de fase que ocorrem na amostra com a variação de temperatura (Haines, 1992). O equipamento utilizado na TGA-DSC foi o analisador térmico simultâneo NETZSCH STA 449 F3 Jupiter ${ }^{\circledR}$.

Área BET, volume de poros e diâmetro médio de poros: Estas análises foram realizadas em equipamento NOVA 1000 series da QUANTACHROME, e analisadas no programa NovaWin versão 10.01 , através das isotermas de adsorção e dessorção de nitrogênio a $-196^{\circ} \mathrm{C}$, para todos os catalisadores. $\mathrm{Na}$ determinação da área específica as amostras foram previamente tratadas a $300{ }^{\circ} \mathrm{C}$ por $5 \mathrm{~h}$ para eliminar a água adsorvida e possíveis condensados existentes nos poros dos sólidos.

Difração de raios X (DRX): Os difratogramas de raios $X$ das amostras calcinadas foram obtidos em um Difratômetro D8 Advance da BRUKER, utilizando radiação $\mathrm{CuK} \alpha(\mathrm{V}=40 \mathrm{kV}, \mathrm{I}=35 \mathrm{~mA})$. Esta análise permite verificar a cristalinidade e as espécies presentes na superfície do sólido analisado.

TPR: Estas análises foram realizadas em um aparelho "home-made" junto ao Departamento de Engenharia Química - UEM. A amostra do catalisador de massa conhecida é colocada em um reator em "U" de quartzo sobre uma placa porosa e é aquecida desde a temperatura ambiente até $1000^{\circ} \mathrm{C}$ a uma taxa de aquecimento de $10^{\circ} \mathrm{C} \mathrm{min}^{-1}$ com um fluxo de gás de $20 \mathrm{~mL} \mathrm{~min}^{-1}$ da mistura de $\mathrm{H} 2 / \mathrm{Ar}(1,75$ e 98,25\%, respectivamente). A localização do termopar é na posição central do leito da amostra e os resultados foram obtidos a partir do consumo de hidrogênio o qual é registrado por um detector de condutividade térmica.

\section{RESULTADOS E DISCUSSÕES}

\subsection{TGA-DSC}

Os resultados de TGA-DSC dos catalisadores HiFUEL W220 e HiFUEL W230 e sol-gel são apresentados nas Figuras 1, 2 e 3. Conforme pode ser observada na Figura 1 a decomposição (ou perda de massa) em todos os catalisadores analisados é muito pequena, sendo mais significativa até $400^{\circ} \mathrm{C}$ e pouco variando a partir deste ponto. De acordo com a Figura 2, ocorreu uma mudança de fase a aproximadamente $280^{\circ} \mathrm{C}$ para ambos catalisadores HiFUEL e outra mudança de fase em aproximadamente $717^{\circ} \mathrm{C}$ para o HiFUEL W220 e $767^{\circ} \mathrm{C}$ para o HiFUEL W230. Entretanto, como as temperaturas reacionais não passam de $300^{\circ} \mathrm{C}$, o catalisador não será utilizado em temperaturas próximas a $700^{\circ} \mathrm{C}$, assim a calcinação pode ser realizada a $400^{\circ} \mathrm{C}$. 


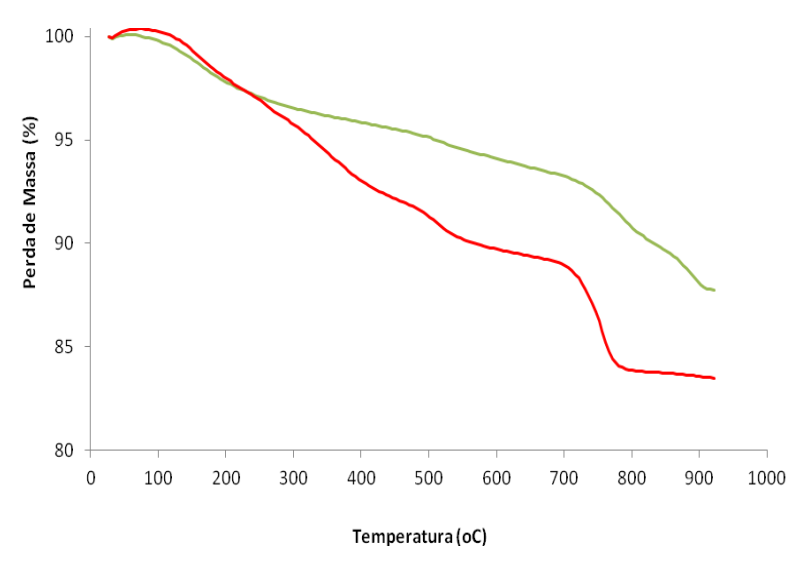

Figura 1 - TGAs dos catalisadores W220 (-), W230 (-).

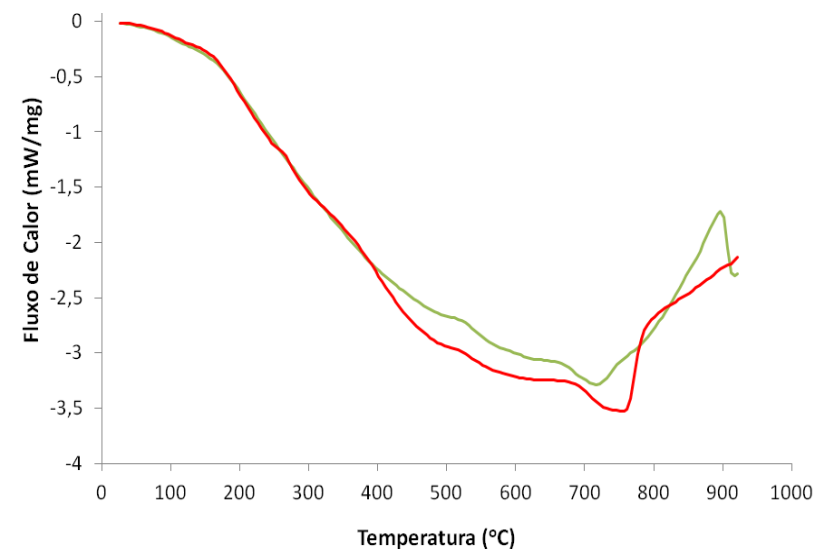

Figura 2 - DSCs dos catalisadores W220 (-), W230 $(-)$.

Levando em conta os resultados obtidos por TGA e DSC apresentados na Figura 3, decidiu-se também calcinar o catalisador com $50 \%$ de $\mathrm{Cu}$ a $400^{\circ} \mathrm{C}$, concluindo-se que até esta temperatura já ocorreram às transições necessárias e que a maior parte dos precursores já foi decomposta. Para a caracterização da cristalinidade destas fases e das estruturas presentes no catalisador final (obtido após a calcinação), foi feita a difração de raios X, discutida no item 3.3.

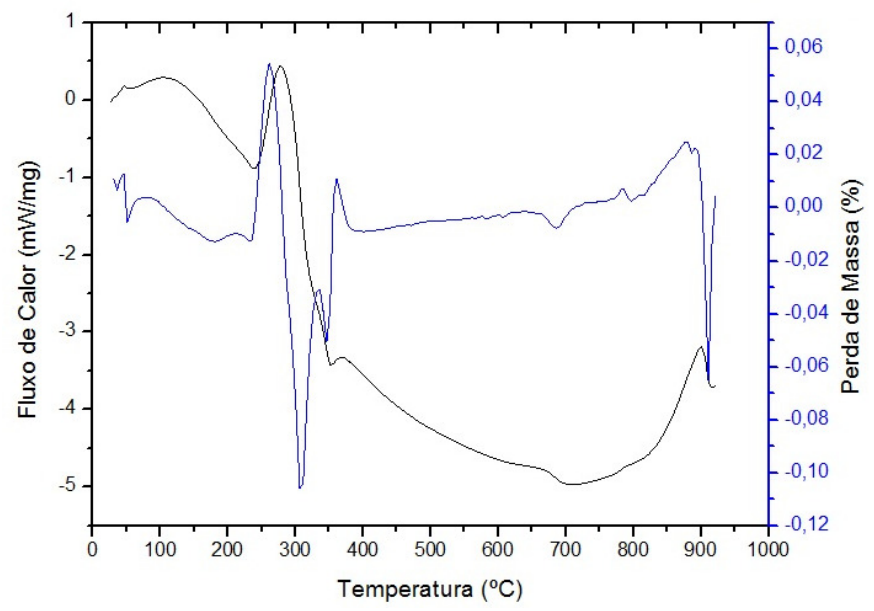

Figura 3 - TGA e DSC para o catalisador sol-gel com composição aproximada a 50\% de Cu.

\section{2. Área BET, Volume Total de Poros e Diâmetro Médio de Poros}


Os resultados das caracterizações texturais de todos os catalisadores analisados são mostrados na Tabela 2, sendo que o catalisador sintetizado pelo método sol-gel foi analisado em dois formatos (pastilhado (P) e não pastilhado (NP)).

Tabela 2 - Análise textural dos catalisadores

\begin{tabular}{|c|c|c|c|c|}
\hline \multicolumn{2}{|c|}{ Catalisador } & Área BET $\left(\mathbf{m}^{\mathbf{2}} \mathbf{g}^{-\mathbf{1}}\right)$ & Volume total de Poros $\left(\mathbf{c m}^{\mathbf{3}} \mathbf{~ g}\right.$ - Diâmetro médio de poros $(\AA)$ \\
\hline \multirow{2}{*}{ Sol-gel } & P & 65,8 & 0,070 & 42 \\
\cline { 2 - 4 } & NP & 94,0 & 0,403 & 171 \\
\hline W220 & 96,57 & 0,106 & 43,98 \\
\hline W230 & 84,38 & 0,082 & 38,86 \\
\hline
\end{tabular}

Com relação à Tabela 2, pode-se observar que o pastilhamento após sua calcinação, para o catalisador sintetizado pelo método sol-gel, reduziu a área superficial, o volume e o diâmetro dos poros. Isso se deve à compressão exercida sobre estes, que faz os átomos e moléculas se reorganizarem mais próximo uns dos outros. Também se percebe que catalisadores com elevadas áreas superficiais específicas podem ser preparados pelo método da mistura química ou sol-gel, pois este método favorece a interação entre a fase metálica e a fase óxida em sistemas metal-óxido por promover o contato íntimo entre estas duas fases, além de permitir modificações nas propriedades estruturais do catalisador (Santos, 1999; Xia et al., 2012; Colpini et al., 2013).

Para os catalisadores industriais, de acordo com Tanaka, et al. (2003), para um catalisador preparado pelo método de co-precipitação com $30 \mathrm{wt} . \% \mathrm{Cu} / 30 \mathrm{wt} \% \mathrm{ZnO} / 40 \mathrm{wt} . \% \mathrm{Al}_{2} \mathrm{O}_{3}$ fornece uma área superficial BET de $118 \mathrm{~m}^{2} \mathrm{~g}^{-1}$. De acordo com o autor, a área de superfície simplesmente diminuiu com um aumento do conteúdo de cobre e óxido de zinco. Guo et al. (2009) também caracterizou amostras calcinadas de catalisadores de $\mathrm{CuO} / \mathrm{ZnO} / \mathrm{Al}_{2} \mathrm{O}_{3}$, obtendo uma área da superfície $\mathrm{BET}$ e o volume de poro com valores de $97 \mathrm{~m}^{2} \mathrm{~g}^{-1}$ e $0,69 \mathrm{~cm}^{3} \mathrm{~g}^{-1}$, para o catalisador calcinado a $350^{\circ} \mathrm{C}$. Uma diminuição da área e do volume de poros foi observada para outras amostras com o aumento da temperatura de calcinação. Os resultados obtidos pelos autores acima citados se aproximam aos apresentados pela Tabela 2. Porém não sabemos ao certo o método utilizado na fabricação do catalisador industrial nem sua temperatura de calcinação.

\subsection{DRX}

Os difratogramas para todos os catalisadores utilizados são apresentados na Figura 4 a seguir e mostram que o catalisador preparado pelo método sol-gel apresentou os picos de $\mathrm{CuO}, \mathrm{ZnO}$ e $\mathrm{Al}_{2} \mathrm{O}_{3}$ mais amplos e definidos, indicando a presença de regiões cristalinas e a superioridade da cristalinidade do catalisador sol-gel em relação aos dois catalisadores comerciais. O HiFUEL W220 apresenta um pico amplo de alumina 


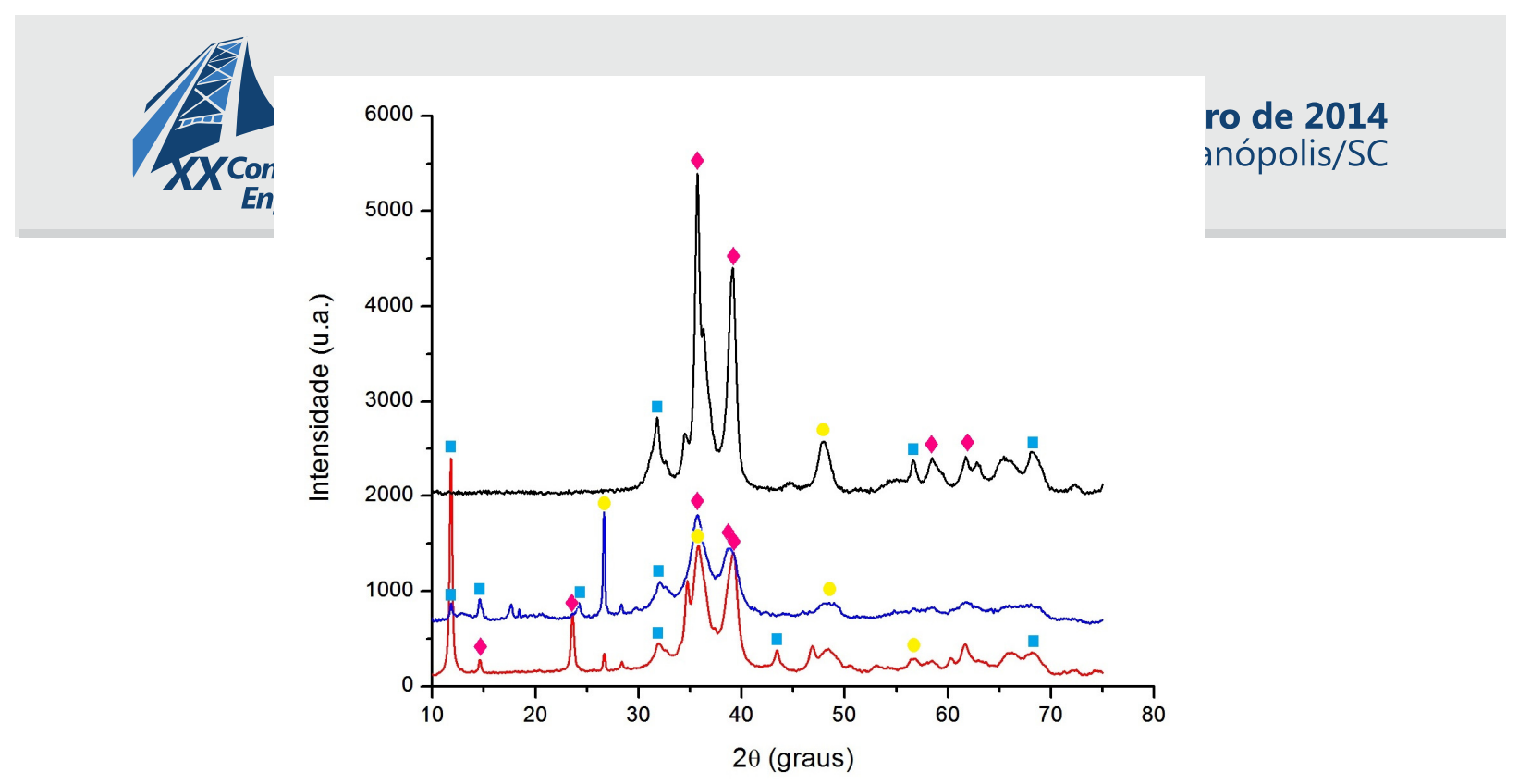

Figura 4 - Difratogramas de raios X dos catalisadores HiFUEL W220 (-), HiFUEL W230 (-) e sol-gel (-) onde indica a $\mathrm{Al}_{2} \mathrm{O}_{3}, \diamond \mathrm{o} \mathrm{CuO}$ e $\odot \mathrm{ZnO}$.

\subsection{TPR} Figura 5.

Os resultados obtidos na análise de TPR para todos os catalisadores utilizados são apresentados na

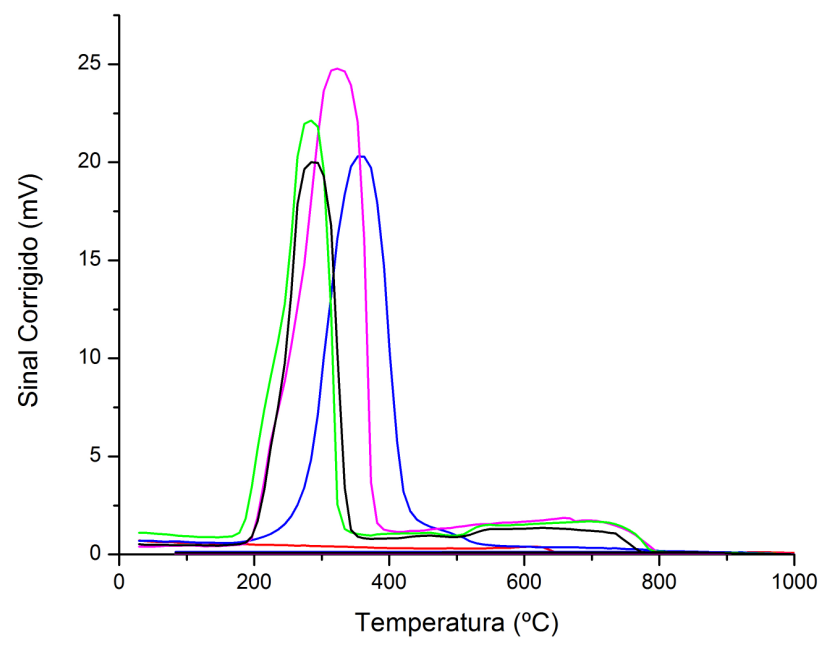

Figura 5 - Gráfico para os TPRs dos catalisadores HiFUEL W220 (-), HiFUEL W230 (-) e sol-gel (-) e para o $\mathrm{ZnO}(-)$ e $\mathrm{CuO}(-)$.

De acordo com a Figura 5, o óxido de cobre reduz dez vezes mais que o óxido de zinco. Todos os catalisadores apresentaram um perfil de TPR com pico de redução bem definido, com o máximo de redução em uma faixa em torno de $190-320^{\circ} \mathrm{C}$. Este comportamento foi relatado por Fiero et al. (1996) que também descreveu um perfil de redução para o $\mathrm{CuO}$ caracterizado por um único e bem afiada pico e para catalisadores com teores altos de $\mathrm{Cu}$ em relação ao $\mathrm{Zn}$ que também são representados por picos individuais e estreitos de redução, porém centrados em temperaturas menores que a encontrada para o $\mathrm{CuO}$ puro . 


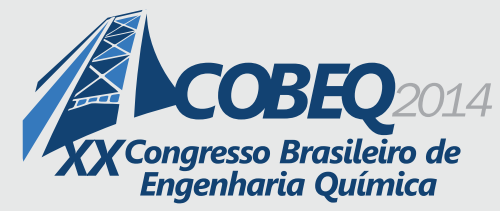

\section{CONCLUSÕES}

Os resultados obtidos para as análises de TGA e o DSC indicaram que para os catalisadores industriais a perda de massa é muito pequena, sendo mais significativa em torno dos $400^{\circ} \mathrm{C}$. Há a ocorrência de uma mudança de fase a aproximadamente $280^{\circ} \mathrm{C}$ para ambos catalisadores HiFUEL e uma outra mudança de fase em temperaturas mais elevadas que a temperatura de reação, ou seja, nãosão importantes para essa análise. Levando-se em conta os TGAs e DSCs para o catalisador sol-gel, decidiu-se calciná-lo a $400^{\circ} \mathrm{C}$.

A maior área superficial BET foi obtida pelo catalisador HiFUEL W220 embora o valor deste parâmetro para o catalisador sol-gel não pastilhado tenha ficado muito próximo. O catalisador sol-gel não pastilhado apresentou volume especifico de poros e diâmetro médio de poros muito superior àqueles obtidos com os catalisadores industriais.

Para a análise de DRX o catalisador sol-gel apresentou maior cristalinidade em relação aos outros. Também se constatou a presença de regiões cristalinas de $\mathrm{ZnO}, \mathrm{Al}_{2} \mathrm{O}_{3}$ e $\mathrm{CuO}$ para todos os catalisadores analisados. Já as análises de redução a temperatura programada revelam que ambos catalisadores comerciais apresentam um pico de redução bem definido com uma faixa de máxima redução entre as temperaturas de 190 a $320^{\circ} \mathrm{C}$.

Com isso, percebe-se a importância dessas caracterizações para a utilização comercial e industrial destes catalisadores, principalmente no que diz respeito as análises onde há vantagens do catalisador solgel em relação aos outros mostrando o grande potencial deste método de síntese e o seu futuro promissor.

\section{REFERÊNCIAS}

ANDREEVA, D.; IDAKIEV, V.; TABAKOVA, T.; ILLIEVA, L.; FALARAS, P.; BOULINOS, A.; TAVBOS, A. Low temperature water-gas shift reaction over $\mathrm{Au} / \mathrm{CeO}_{2}$ catalysis. Catalysis Today, v. 72, p. 51-57, 2002.

BUNLUESIN, T; GORT, R. J.; GRAHAM, G. W.; Studies of the water-gas shift reaction on Ceriasupported Pt, Pd and Rh: Implications for oxygen-storage properties. Applied Catalysis B: Environmental, v. 15, p. 107-114, 1998.

COLPINI, L. M. S.; LENZI, G. G.; MARTINS, L.; GONZÁLEZ, E. A. U.; SANTOS, O. A. A. e COSTA, C. M. M. Selective catalytic reduction of $\mathrm{NO}$ with propane on $\mathrm{V}_{2} \mathrm{O}_{5} / \mathrm{SiO}_{2}, \mathrm{~V}_{2} \mathrm{O}_{5} / \mathrm{TiO}_{2}$, and $\mathrm{V}_{2} \mathrm{O}_{5} / \mathrm{Al}_{2} \mathrm{O}_{3}$ catalysts obtained through the sol-gel method. Acta Sci. Tech., v. 15, p. 139-145, 2013.

FIERO, G.; JACONO, M. Lo.; INVERSI, M.; PORTA, P.; CIOCI, F. e LAVECCHIA, R. Study of the reducibility of copper in $\mathrm{CuO}-\mathrm{ZnO}$ catalysts by temperature-programmed reduction. Applied Catalysis A: General, v. 137, p. 327-348, 1996.

GONÇALVES, G.; LENZI, M. K.; SANTOS, O. A. A. e JORGE, L. M. M. Preparation and characterization of nickel based catalysts on silica, alumina and titania obtained by the sol-gel method. Jour. of Non-Cryst. Solids, v. 352, p. 3697-3704, 2006. 
GUO, P.; CHEN, L.; YANG, Q.; QIAO, M.; HUI, L.; LI, H.; XU, H.; FAN, K. Cu/ZnO/Al ${ }_{2} \mathrm{O}_{3}$ water-gas shift catalysts for practical fuel cell applications: the performance in shut-down/start-up operation. International Journal of Hydrogen Energy, v. 34, p. 2361 -2368, 2009.

HAINES, P. J. Principles of Thermal Analysis and Calorimetry. Cambridge, UK: Lynx Edicions, 1992.

KORYABKINA, N. A.; PHATAK, A. A.; RUETTINGER, W. F., FARRAUTO, R. J.; RIBEIRO, F. N. Determination of kinetic parameters for the water-gas shift reaction on copper catalysts under realistic conditions for fuel cell applications. Journal of Catalysis, v. 217, p. 233-239, 2003.

LENZI, G. G. ; Fávero, C.V.B. ; Colpini, L.M.S. ; Bernabe, H. ; Baesso, M.L. ; Specchia, S. ; Santos, O.A.A. . Photocatalytic reduction of $\mathrm{Hg}(\mathrm{II})$ on $\mathrm{TiO} 2$ and $\mathrm{Ag} / \mathrm{TiO} 2$ prepared by the sol gel and impregnation methods. Desalination (Amsterdam), v. 270, p. 241-247, 2011.

MACIEL, C. G.; SILVA, T. de F.; ASSAF, E. M.; ASSAF, J. M. Hydrogen production and purification from the water-gas shift reaction on $\mathrm{CuO} / \mathrm{CeO}_{2}-\mathrm{TiO}_{2}$ catalysts. Applied Energy, v. 12, p. 52-59, 2013.

Nele, M.; Moreno, E. L. ; Andrade, H. M. C. Química Nova, 2006.

PEARSON, I. M.; RYU, H.; WONG, W. C. e NOBE, K. Chemical Mixed' Catalysts. Ind. Eng. Chem. Prod. Res. Dev., v. 22, p. 381-382, 1983.

SANTOS, O. A. A. Hidrogenação Seletiva do Ácido Oléico em Catalisadores de Rutênio. Tese de Doutorado, Universidade Estadual de Campinas, 1999.

SUN, J.; QIU, X.; WU, F.; ZHU, W.; WANG, W.; HÃO, S. Hydrogen from steam reforming of ethanol in low and middle temperature range for fuel cell application. International Journal of Hydrogen Energy, v. 29, p. 1075-1081, 2004.

TANAKA, Y.; UTAKA, T.; KIKUCHI, R; SASAKI, K.; EGUCHI, K. CO removal from reformed fuel over $\mathrm{Cu} / \mathrm{ZnO} / \mathrm{Al}_{2} \mathrm{O}_{3}$ catalyts prepared by impregnation and coprecipitation methods. Applied Catalysis A: General, v. 238, p. 11-18, 2003.

UTAKA, T.; SEKIZAWA, K.; EGUCHI, K. CO removal by oxygen-assisted water-gas shift reaction over supports Cu catalysts. Applied Catalysis A:General, v. 194-195, p. 21-26, 2000.

\section{AGRADECIMENTOS}

Os autores agradecem à CAPES - Brasil pelo apoio financeiro. 